\title{
SENTIR O SENTIDO: A EXPERIÊNCIA DO CÓDIGO NOS HOMEÓSTATOS DE JOSÉ-ALBERTO MARQUES
}

Manuel Portela*

RESUMO: Este breve ensaio analisa a série de poemas Homeóstatos de José-Alberto Marques como motores textuais. Ao tornar o código numa componente do texto, os Homeóstatos tipificam o poema experimental como uma investigação sobre a linguagem, a escrita e a leitura. A espacialização do texto na página é ativada de modo a produzir efeitos gerativos, combinatórios e ideogramáticos. Simultaneamente textos e instruções para gerar textos, os Homeóstatos constituem um exemplo de uma poética informacional que tira partido da dinâmica entre poema e sistema da língua para explorar os atos de escrita e leitura como processamento de sinais.

Palavras-chave: Homeóstatos. José-Alberto Marques. Poesia Experimental Portuguesa.

Escrever homeostaticamente é tentar chegar à fonte, impossível de tocar, da própria linguagem. É tentar chegar a esse momento articulatório em que o traço fonografémico institui o sistema de diferenças que, a partir de um conjunto limitado de elementos, origina a profusão de formas das línguas. Desse momento inicial, inscrito geneticamente nas áreas e circuitos cerebrais de onde emergem as línguas naturais humanas, e reinscrito nos sistemas de notação que as recodificam, só posso ter uma experiência simulada ao observar a infinita combinatória de sinais que sustém a cadeia da linguagem. A invenção da escrita e do alfabeto exteriorizaram a diferencialidade fonossemântica dos processos neuronais que sustentam o pensamento simbólico e as suas complexas cascatas de significação e ressignificação. Escrever é entregar-me à força gerativa e incontrolável desse código, submetendo a singularidade da experiência subjetiva aos seus mecanismos autopoiéticos e probabilísticos.

Ao transformarem uma sequência de palavras num gerador textual, os Homeóstatos

\footnotetext{
${ }^{*}$ Faculdade de Letras da Universidade de Coimbra, Portugal. E-mail: mportela@fl.uc.pt (cc) EY-NC-ND

Esta obra está licenciada com uma licença Creative Commons. 
de José-Alberto Marques (1967) permitem visualizar o código genético da língua, com base numa amostra da produtividade gerativa do código de sinais que o alfabeto constitui. Esta possibilidade simulatória de capturar a replicação molecular e celular da língua depende ainda da intensificação da consciência do código alfabético materializado na máquina de escrever. Colocando nas mãos do escritor os sinais individualizados do alfabeto, o teclado oferece-Ihe a experiência tátil e háptica da escrita como recombinação informacional de sinais ("neve: vento. alguém. teus pés. ombros. frio: cabelos de serpente").

O monoespaçamento das letras na página, que me indica tratar-se da replicação das mesmas letras nas mesmas posições relativas em diferentes áreas da folha de papel, mostra-me que foi a partir da grelha cartesiana instituída pela mecânica funcional da máquina de escrever que o código alfabético se pôde tornar autorreflexivo. Os Homeóstatos revelam a digitalidade computável da língua, através de uma representação diagramática que visualiza uma distribuição probabilística da ressequenciação das letras em novas palavras ou da sua reconstelação em novos ideogramas.

Esta analogia genética pode alargar-se aos mecanismos de replicação do ADN: a linha matriz (horizontal ou vertical) de cada Homeóstato torna-se ela própria no genoma do poema, a partir do qual as diferentes unidades de inscrição-sentido podem ser geradas. As matrizes teriam portanto a função de regular o equilíbrio interno do poema enquanto sistema. Cada seccionamento de carateres e cada recombinação semântica ou visual resultante desse seccionamento representaria novas células de inscrição-sentido construídas com base no código original ("sem luz. a noite acontece. ventre escuro. sombra: neve. alguém: o teu grito"). 
Fig. 1 - Homeóstato 6, José-Alberto Marques, 1965. Imagem de Operação 1 (1967).

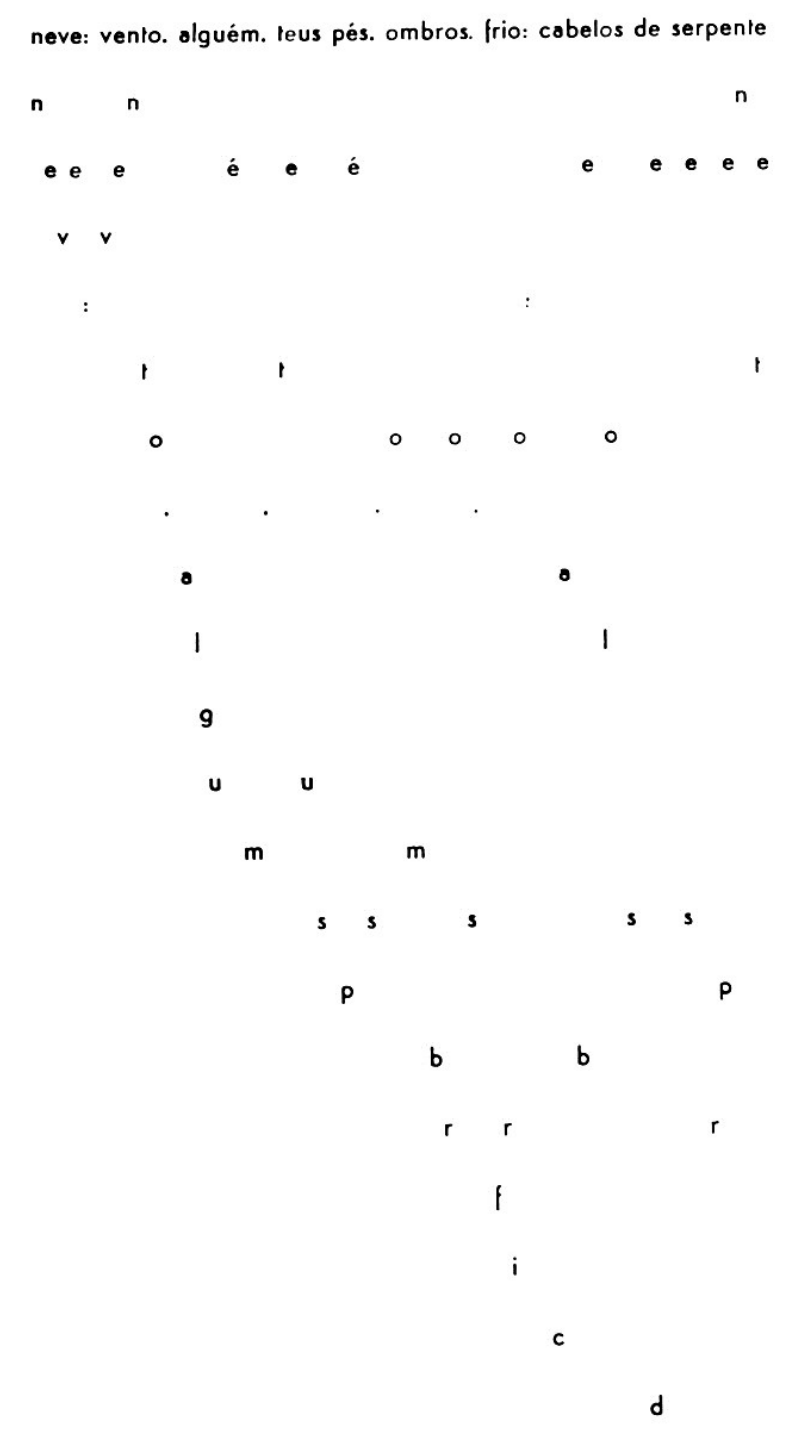

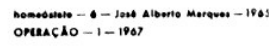

Texto Digital, Florianópolis, Santa Catarina, Brasil, v. 12, n. 1, p. 69-78, jan.jjun. 2016. ISSNe: 1807-9288. 
Fig. 2 - Homeóstato 1, José-Alberto Marques, 1965. Imagem de Operação 1 (1967). Também publicado em Poesia Experimental 2 (1966); Antologia da Poesia Concreta em Portugal (1973); Antologia da Poesia Experimental Portuguesa Anos 60 - 80 (2004).

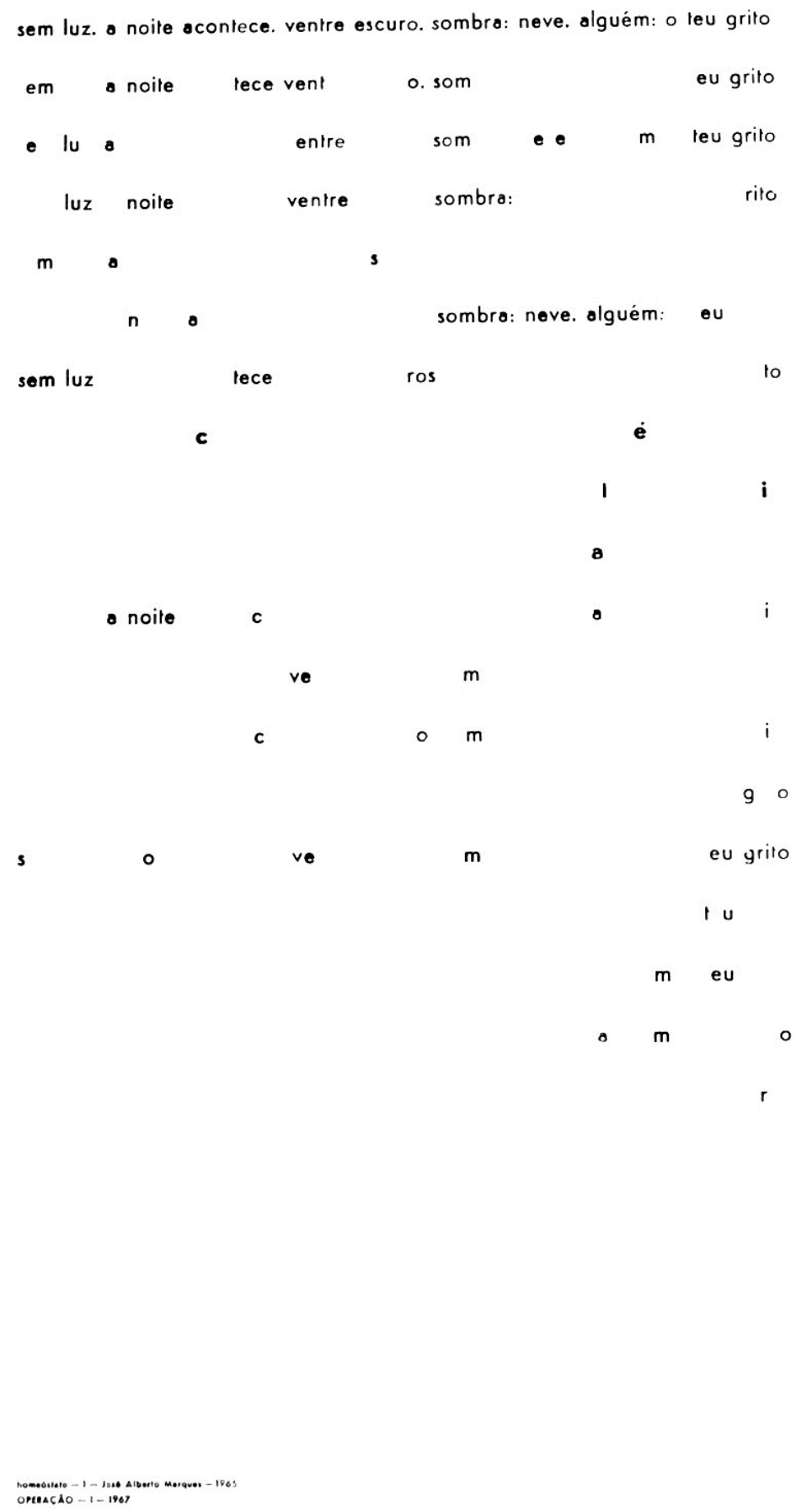


Ao leitor é dada a consciência material da palavra enquanto inscrição e do código que gera a palavra. A demonstração do alfabeto e da língua enquanto códigos não se limita a sublinhar a natureza da palavra como produto da agregação cibernética de sinais. É dada também ao leitor a consciência da leitura e do processo de articulação de sinais que a leitura constitui: juntar e separar letras, juntar e separar espaços em branco, otimizar o rácio entre redundância e ruído, isto é, processos que permitem tornar os elementos textuais em objetos de perceção e cognição capazes de ativar, a partir da notação gráfica, os múltiplos eixos e hierarquias de articulação da linguagem. Nesta relação dinâmica com a espacialização, num mesmo plano, do código e da mensagem, o sentido é experimentado como um processo de construção na superfície da página.

A combinatória permite encontrar palavras dentro de outras palavras ou sequências de palavras, fazendo-as derivar da sequência de carateres inicial, através de um processo de segmentação, transposição e reassociação, similar aos processos replicativos bioquímicos. Esta molecularização simulatória das unidades da linguagem torna possível visualizar a natureza homeostática de todo o sistema, cujo equilíbrio dinâmico resulta da relação entre o código e as suas múltiplas instanciações materiais. A coalescência temporária das letras em novas unidades semânticas ou visuais de sentido, que o leitor percebe (retrospetivamente) como estando microscopicamente aninhadas no código linear ou constelado, sugere também a sua natureza probabilística: certas combinações cristalizam sequências fonografémicas coincidentes com palavras, mas é possível perceber-se um campo combinatório mais vasto de sequências assémicas não cristalizadas como palavras. De modo semelhante, a perceção das constelações oscila entre a microapreensão letra a letra e a macroapreensão do padrão ideográfico. O sentido emerge como um certo número de possibilidades, linguística e visualmente realizadas a partir da infinitude gerativa do código.

Ao usar uma linha como matriz e código de todo o texto, explorando as permutações ou replicações consteladas de letras contidas nessa linha ("vermelhos teus sonhos de lume: liberdade quente: ossos"), os Homeóstatos oferecem uma experiência radical da textualização do sentido, isto é, da produção a posteriori da subjetividade, a partir 
de um sistema de inscrições no qual a leitura tem também de se inscrever.

Fig. 3 - Homeóstato 2, José-Alberto Marques, 1965. Imagem de Operação 1 (1967). Também publicado em Antologia da Poesia Concreta em Portugal (1973).

eu

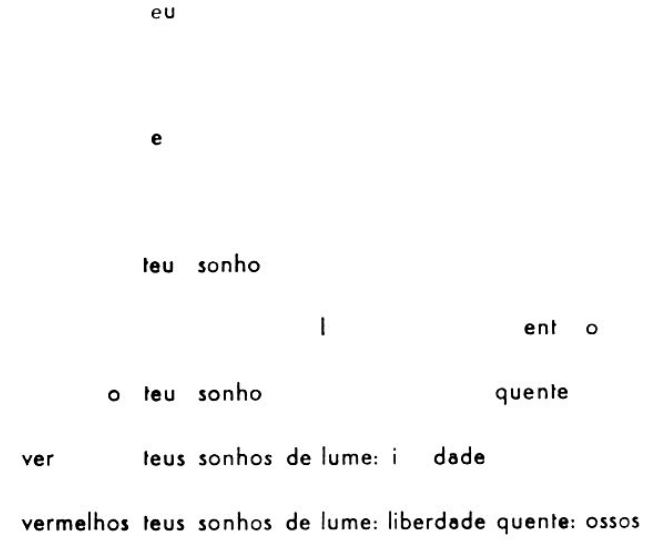

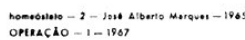

Texto Digital, Florianópolis, Santa Catarina, Brasil, v. 12, n. 1, p. 69-78, jan./jun. 2016. ISSNe: 1807-9288. 
O texto produz-me como sujeito no ato de executar o seu programa. Ao invés de ser anterior à expressão, o sentido surge antes como um produto residual da própria expressão, excesso semântico imprevisto e exploratório, resultado quase acidental da recombinação de letras e da emergência de inscrições-sentido nessa recombinação. Por isso, este modo de construção me faz sentir o sentido, num loop metacognitivo que me permite perceber-me a ler e a inventar o sentido da escrita.

Esta intensificação da experiência do texto enquanto espaço de iteração e código de geração de sentido não deixa, no entanto, de referir a experiência subjetiva do mundo. Os campos semânticos introduzidos pelas dez linhas de código que controlaram as permutações e constelações contêm as referências necessárias à ancoragem experiencial do sentido, seja pelos campos semânticos das palavras ("sem luz. a noite acontece. ventre escuro. sombra: neve. alguém: o teu grito"), seja pela evocação mimética dos sons ("a secura da pedra /a voz misteriosa /reflecte /o grito lento"), seja ainda pela reconfiguração ideogramática das letras ("amor. tu. leve. braços sexo. teu nome. distância" e "nu. o homem vertical. válido").

A tematização da experiência do amor sexual surge, de resto, nas três estratégias de representação - semântica, sonora e visual - e percorre vários textos. Os Homeóstatos parecem assim procurar uma linguagem para a experiência do corpo e dos sentidos, evocando-a e simulando-a através das tensões gráficas, semânticas e sonoras do texto, como se na espacialização e na sonorização das letras da escrita pudesse ser capturada e emulada a autoconsciência do enlace sexual. 
Fig. 4 - Homeóstato 7, José-Alberto Marques, 1965. Imagem de Operação 1 (1967).

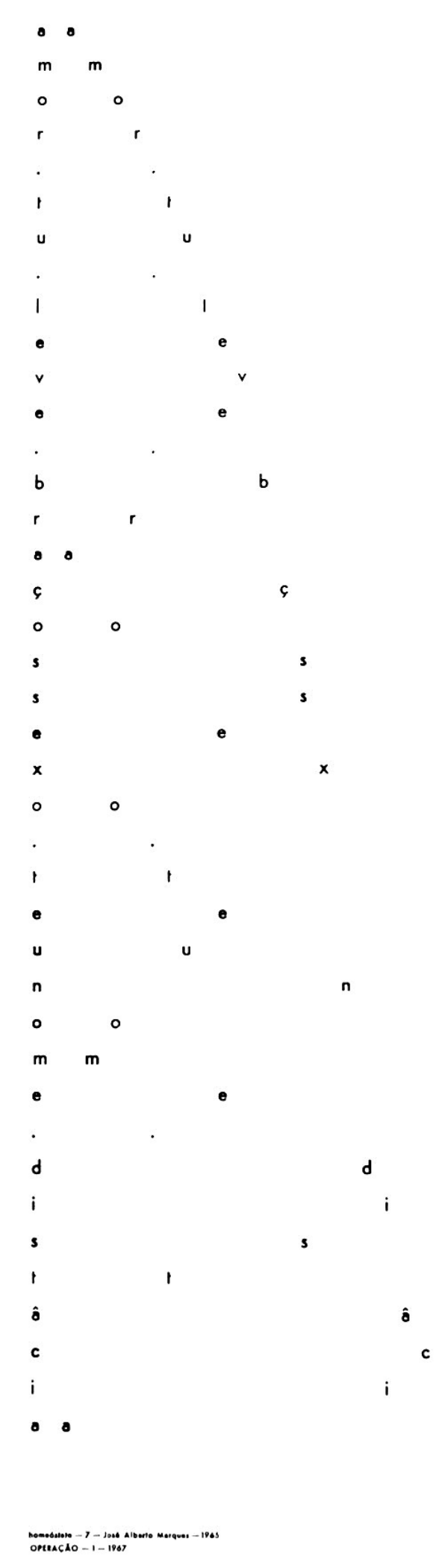

Texto Digital, Florianópolis, Santa Catarina, Brasil, v. 12, n. 1, p. 69-78, jan.jun. 2016. ISSNe: 1807-9288. 
Na sua tripla lógica combinatória, gerativa e constelada, o equilíbrio homeostático pode ser entendido em dois níveis distintos: por um lado, como equilíbrio dinâmico entre o sistema do poema e o sistema da língua, que abre as permutações contidas no código letrístico do poema ao vasto sistema da língua, mostrando as possibilidades de circulação recursiva entre um e outro; por outro lado, como equilíbrio interno ao próprio sistema do poema, que controla a aleatoriedade de uma combinatória meramente fatorial das letras com um conjunto de restrições, que limitam a proliferação semiótica através de unidades de inscrição-sentido, semanticamente dependentes do campo de experiência evocado nas palavras da linha de código, ou por meio de constelações visuais que reorganizam as letras numa ordem ideogramática de figuração ${ }^{1}$. Deste modo, o poema homeostático funciona como modelo textual da otimização da relação dinâmica entre experiência do sentido e sentido da experiência. É neste ponto de tensão entre código e texto que o motor da linguagem e a invenção do sentido se tornam, por instantes, observáveis.

\section{SENSING SENSE: THE EXPERIENCE OF CODE IN JOSÉ-ALBERTO MARQUES' HOMEÓSTATOS}

ABSTRACT: This brief essay analyzes the series of poems Homeóstatos by José-Alberto Marques as textual engines. By turning the code into a textual component, the homeóstatos show the experimental poem as an investigation into language, writing and reading. The spatial distribution of text on the page is activated in order to produce generative, combinatorial and ideogrammatic effects. Working simultaneously as texts and instructions for generating texts, the homeóstatos are an example of an informational poetics that takes advantage of the dynamics between poem and linguistic system to explore writing and reading acts as signal processing.

KEYWORDS: Homeóstatos. José-Alberto Marques. Portuguese Experimental Poetry.

\footnotetext{
1 Tomando como base os 10 homeóstatos de José-Alberto Marques, o Gerador de homeóstatos (http://telepoesis.net/homeostatos/), de Rui Torres (2015), explicita a função codificadora da linha sequencial de texto em alguns dos homeóstatos originais ( $n^{\circ} s$ 1, 2, 3, 4, 5, 6 e 10), programando quer novas matrizes, quer novas permutações das letras contidas nessas matrizes. Esta versão programada formaliza o modelo textual do original, demonstrando a relação nele contida entre o motor textual e as instanciações textuais geradas pela recombinação dos seus caracteres em novas unidades de inscrição-sentido, isto é, a presença simultânea do texto-código e do texto gerado pelo código. Todavia, em cada novo homeóstato gerado, a seleção de carateres para formar novas palavras é feita a cada linha (e não com uma lógica sintática e semântica que seja independente da divisão de linhas e da mera formação permutativa de palavras), alterando quer o equilíbrio interno do poema, quer o equilíbrio entre o sistema do poema e o sistema da língua, a favor da aleatoriedade e da omnipresença do sistema linguístico.
} 


\section{Referências}

MARQUES, José-Alberto. 9 homeóstatos. Operação 1, s.n., 1967, in CD-ROM da PO-EX (Poesia Experimental Portuguesa - Cadernos e Catálogos), Porto, Universidade Fernando Pessoa, 2009. Disponível em: <http://www.poex.net/evaluation/>. Acesso em: 30 mai. 2015.

TORRES, Rui. Gerador de Homeóstatos, a partir de José-Alberto Marques, 2015, in Arquivo Digital da PO.EX, Porto, Universidade Fernando Pessoa, 2014-2016.

Disponível em: <http://po-ex.net/taxonomia/materialidades/digitais/rui-torres-nunoferreira-gerador-de-homeostatos>. Acesso em: 30 mai. 2015.

Aceito em: 19/05/2016. Recebido em: 26/06/2016. 